\title{
INTERNATIONAL SYMPOSIUM ON MACROMOLECULES, WIESBADEN
}

$\mathrm{T}$ HE annual International Symposium on Macromolecules, held under the auspices of the Commission on Macromolecules of the International Union of Pure and Applied Chemistry, this year took place in Wiesbaden, Germany, during October 12-17. Almost 1,200 people registered for the Conference, which must have been the largest of this series ever held. About half the delegates were from Germany and the remainder came from twenty-four other countries, with France, the United States and Great Britain supplying the largest delegations.

Organization of a symposium on the above scale must obviously be highly efficient if the work of the Conference is to be carried out, and the organizers deserve the highest credit for the arrangements they made. Meetings were held mainly in two large halls in the magnificent new Rhein-Main Halle, the acoustics of which were excellent. The general plan of the meetings was as follows. The Symposium was divided into five sections: (1) Physics of Macromolecular Substances; (2) Macromolecular Substances in Solution; (3) Elementary Processes and Kinetics of Polyreactions ; (4) Chemistry of Organic and Inorganic Macromolecular Substances; and (5) Macromolecular Natural Substances and Model Compounds. Every day, a plenary lecture was given on some topic from one of the five sections. For the remainder of the morning, sessions of two sections were held simultaneously, at each of which three lectures were given that were essentially reviews rather than original scientific papers. In this way, practically the whole of the current field of polymer progress was summarized. The official languages of the Symposium were German, French and English, and during the morning sessions, translations of the text of the lectures were projected on to two screens behind the speaker, the third central screen being reserved for slides. On the whole, the system worked very well, provided the lecturer stuck to his text.

The afternoons were devoted to consideration of the numerous short communications ; in each of the five main sections, about forty communications, which were intermediate in length and character between a paper and an abstract, had been submitted. Discussions of at least two, and sometimes three, sections were held simultaneously in the various halls, about twelve short papers, together with the morning lectures, being discussed at each session. While at some sessions the time allocated for discussion was more than adequate, at others the time for discussion of some papers was quite inadequate, and the chairman seemed more concerned to keep to his average 'driving speed' than to promote full discussion. This is a problem that besets all conferences, but perhaps the very size of this one made flexibility of arrangements more difficult. (It is only fair to say that numerous participants of the Symposium found no fault at all with the arrangements for discussions.)

Faced with more than thirty full lectures, and two hundred short communications, even the most indefatigable student of macromolecules feels surfeited, and becomes highly selective in his attendance. For this reason, and because at least two sessions were held simultaneously both in the morning and afternoon, I cannot give a full account of all aspects of the Symposium. The following summary covers what seemed the most interesting and significant features of the lectures and papers.

In the field of the physics of polymers, there was considerable interest and activity in studies of the mechanism of crystallization and the morphology of crystalline polymers. The lectures by $\mathbf{A}$. Keller (of Bristol) and W. A. Kargin (of Moscow), in particular, aroused lively discussions. Kargin and also S. R. Usmanov (of Tashkent) presented the case that polymers that are normally regarded as partly crystalline, such as cellulose, are not truly crystalline in any sense, since they do not pass certain thermodynamical criteria, such as the presence of transition points, and should be regarded only as highly ordered. Keller reviewed current opinions on the structure of spherulites and the exciting recent developments in forming macro-crystals of polymers in which the polymer chains are folded back on themselves. The other main branches of physics on which attention was centred were dielectric and mechanical relaxation phenomena, nuclear magnetic resonance, and the thermal behaviour of polymers.

The study of the properties of solutions of polymers obviously still commands considerable attention, from both the theoretical and the practical points of view. P. Debye (of Ithaca) presented a new method of estimating molecular interactions from measurements of light scattering, and this gave hope that ultimately a new experimental tool for estimating intermolecular forces would develop. Rheological and viscosimetric studies, and in particular the deduction of molecular dimensions from these, comprised one section, while another dealt with the thermodynamics of polymer solutions, and the quanti. tative determination of parameters such as the virial coefficients, etc. Of considerable interest to experimentalists were a lecture by F. Patat (of Munich) reviewing osmotic pressure techniques and results, and papers by C. Kruissink (of Delft) on the theory, and H.-G. Elias (of Munich) on the practice, of using membranes partially permeable to the solute. Further refinements of conventional methods of measuring molecular weights and molecular weight distributions were described, but there did not seem to be any major new developments in this field.

In the section on elementary processes and kinetics of polyreactions, several lively sessions were held. One topic that naturally aroused much interest was ionic polymerization, with special reference to stereospecific polymerization. Valuable interpretative reviews were given by G. Natta (of Milan) on stereospecific polymerization, M. Szwarc (of Syracuse, U.S.A.) on anionic polymerization, and M. Magat (of Paris) on ionic polymerization initiated by ionizing radiation. There were also, of course, numerous short contributions on these topics. Ionic polymerizations are attracting considerable attention at present, as a result of the enormous commercial developments following the pioneer work of Ziegler and Natta, and it is certain that, despite the enormous work effort, much yet remains to be discovered. The present conference provided some evidence that development 
has outpaced theory and interpretation, and once this is remedied, and the runners in the race get their second wind, more exciting progress will be made.

Fortunately 'steam-radio' (that is, free radical) vinyl polymerizations continue to be studied, with the work perhaps best described as being in the consolidation state. Valuable reviews of the applications to polymer studies of radioactive labelling and electron spin resonance were provided by J. C. Bevington and D. H. Whiffen, respectively (both of Birmingham). The industrially very important process of polymerization in heterogeneous media attracted some attention.

A session was held on the polymerization of caprolactam, at which all the papers were given by workers on the Continent.

One section was devoted to the discussion of natural polymers and model substances. W. Kuhn (of Basle) gave a fascinating lecture on the production of mechanical energy by macromolecular systems. Current interest in polypeptides was reflected by lectures by T. Wieland (of Frankfurt) on the organic chemistry of the formation of peptide links and $\mathrm{C} . \mathrm{H}$. Bamford (of Maidenhead) on synthetic polypeptides. In these two lectures, a fascinating contrast between the ingenuities of the organic and the physical chemist was displayed. Close as are these two studies to the processes of life itself, some studies that were reported on nucleic acids, cancer, and enzyme action were even closer, and demonstrated the extensive range of topics to which polymer science has a major contribution to make.

Starch and cellulosic chemistry was also treated in several contributions and lectures by E. Husemann (of Freiburg) and H. Sihtola (of Helsinki). One interesting new discovery by $\varnothing$. Ellefsen (of Oslo) was the preparation of a new crystalline modification of cellulose. Only a few papers were given on rubber, including a review by W. F. Watson (of Shawbury) of recent work on the mechanochemical reactions of polymers.

A very interesting section was that on what might be termed the preparative chemistry of organic and inorganic polymers. A review of new condensation polymers was given by $\mathrm{H}$. Mark (of New York); this included an elegant demonstration of 'interfacial polycondensation', by means of which high-molecular weight polyamides are formed virtually instantaneously at room temperature. The happy term 'Instant Nylon' has been coined in the United States for this polymer. The application of classical organic reactions to vinyl polymers leads to many interesting new products, and progress in this field was summarized by G. J. Smets (of Louvain). Considerable interest is boing currently shown in inorganic, and organic/inorganic polymers, and this was reflected in numerous short papers as well as set lectures by E. Thilo (of Berlin), H. Deuel (of Zurich), H. Krebs (of Bonn) and S. Nitzsche (of Burghausen). Various unusual organic polycondensation reactions, and methods of forming cross-linked polymers and block copolymers, also received attention.

It will be obvious from the above, highly inade. quate, summary that there was scarcely an aspect of polymer science that did not receive attention. Whether this is the best programme for a conference is a matter for debate, as it can be argued that limitation of the subject-matter promotes a fuller and deeper discussion. There can be no doubt, however, that the Symposium once again fulfilled its main purpose of bringing together polymer scientists and promoting fertile interchanges of views.

Some of the main lectures have already appeared in Die Makromolekulare Chemie, and the remainder, together with the discussions, will appear in later issues.
L. VaLentine

\section{INDUSTRY AND THE TECHNICAL COLLEGES IN BRITAIN}

\begin{abstract}
$\mathrm{A}^{\mathrm{N}}$ $\mathrm{N}$ important paper on the relationship between industry and technical colleges was presented at a conference arranged by the Liverpool District of the Federation of British Industries at Chester on October 21. The speaker, Mr. L. S. Newton, of Pilkington Bros., Ltd., suggested that, despite the increased attention being paid by industry to the education and training of its personnel, there are three ways in which many firms are still not making a real contribution to the development of the educated man-power of Great Britain.

Many firms are still evading their responsibility for training young people and are content to recruit their craftsmen, technicians and technologists from other companies. Industry should accept the opportunity provided by the 'bulge' to analyse its requirements for the next ten to fifteen years to see how many young people it could now absorb to train for later years. Many firms also do not provide facilities for part-time release for study in the day-time-this applies not only to industry but also to professional and commercial undertakings. Industry frequently fails to discriminate between the branches of study, the facilities for commercial students remaining quite inadequate.
\end{abstract}

A feature of post-war development has been the remarkable rise in the number of students being released for sandwich courses. The number of students attending the technical colleges full-time or on a sandwich basis has risen tenfold in the past twenty years, between 80 and 90 thousand being in attendance at the moment. What the ultimate ratio should be has not yet become clear, but industry's support for sandwich courses is far from uniform and largely in the hands of the larger and more progressive companies.

Mr. Newton's most important contribution to the conference, however, was concerned with the ways in which closer co-operation between industry and the technical colleges could be achieved.

There are four main places where action could be taken to establish, maintain and foster relationships between the two bodies for their mutual benefit: (a) there should be a closer tie at the policy-making level; $(b)$ there should be a closer tie at the point at which the contents of syllabuses and courses are determined; (c) there should be a closer tie at the teaching level; and $(d)$ there should be a greater sharing of responsibility for the success of the student. 